\title{
A randomised trial comparing mesalazine and prednisolone foam enemas in patients with acute distal ulcerative colitis
}

\author{
F I Lee, D P Jewell, V Mani, M R B Keighley, R D Kingston, C O Record, R H Grace,
} $S$ Daniels, J Patterson, K Smith

\begin{abstract}
Distal ulcerative colitis can be treated with oral or rectal mesalazine, or both. A foam enema preparation has been developed and its efficacy investigated. The aim of this study was to evaluate the efficacy and safety of mesalazine foam enemas compared with prednisolone foam enemas in the treatment of patients with acute distal ulcerative colitis. Patients aged over 18 years presenting with a relapse of distal ulcerative colitis were randomly allocated treatment with mesalazine foam enema $(n=149$ evaluable patients) and prednisolone foam enema $(n=146$ evaluable patients) for four weeks. A randomised multicentre investigator blind parallel group trial was conducted. It was found that after four weeks of treatment, clinical remission was achieved by $52 \%$ of mesalazine treated patients and $31 \%$ of patients treated with prednisolone $(p<0 \cdot 001)$. There was a trend in favour of more patients in the mesalazine group achieving sigmoidoscopic remission $(40 \%$ v $31 \%, p=0 \cdot 10)$. Histological remission was achieved by $27 \%$ and $21 \%$ of patients receiving mesalazine and prednisolone respectively. Symptoms improved in both treatment groups. Significantly more mesalazine patients had no blood in their stools after four weeks of treatment $(67 \%$ $v 40 \%, p<0.001)$. Prednisolone treated patients had significantly fewer days with liquid stools than mesalazine patients, with a median of 0 and 1 days respectively by week $4 \quad(p=0 \cdot 001)$. In this study mesalazine foam enema was superior to prednisolone foam enema with regards to clinical remission, this was supported by favourable trends in sigmoidoscopic and histological remission rates. Both treatments were well tolerated. (Gut 1996; 38: 229-233)
\end{abstract}

Keywords: mesalazine foam enema, distal ulcerative colitis, randomised, controlled trial.

Ulcerative colitis is a chronic, recurrent disease of unknown aetiology in which part or all of the mucosa of the colon and rectum becomes inflamed. Distal ulcerative colitis refers to inflammation confined to the rectum, sigmoid, and descending colon. The principal symptoms are diarrhoea with urgency of defecation and rectal bleeding.
Mesalazine (5-aminosalicylic acid, 5-ASA) is the active moiety of a variety of aminosalicylic based drugs for inflammatory bowel disease. The efficacy of mesalazine is due to its topical action, and various methods and delivery systems have been used to get the active constituents specifically to the inflamed mucosa (that is, combination with a sulphapyridine carrier, enteric coating, slow release formulations, enemas, and suppositories).

The use of oral mesalazine in the treatment of ulcerative colitis is now well established. ${ }^{1-3}$ In cases of acute distal colitis, a corticosteroid enema is often added to the background of oral mesalazine. Liquid mesalazine enemas are available and have been shown to be superior to placebo ${ }^{4}$ and as effective as corticosteroid enemas at inducing remission in acute mild to moderate distal ulcerative colitis. ${ }^{67}$ Liquid enemas are difficult to retain, however, requiring patients to lie down for at least 30 minutes, and a recent study showed that patients prefer foam rather than liquid enemas. ${ }^{8}$

We conducted a randomised investigator blind parallel group trial in 295 evaluable patients with acute distal ulcerative colitis and evaluated the efficacy and safety of mesalazine foam enema (Asacol) compared with a commercially available prednisolone foam enema (Predfoam).

\section{Methods}

The study was conducted in patients aged 18 years and above attending outpatient clinics in 39 centres in the United Kingdom between October 1990 and June 1993.

To be eligible for the trial, patients had to have a confirmed diagnosis of distal ulcerative colitis that did not extend beyond the splenic flexure and be in a state of clinical and sigmoidoscopic relapse. Patients were excluded if they had taken oral or rectal corticosteroids or rectal 5-ASA preparations in the month prior to entry or required such treatment during the course of the study, had severe allergy or bronchial asthma, had a known hypersensitivity to corticosteroids or salicylates, had a specific cause of their colitis, for example, Crohn's colitis, had any clinically significant cardiac, hepatic or renal disease or were pregnant, lactating or not using reliable contraception. Maintenance treatment of oral mesalazine or sulphasalazine was permitted provided this treatment had been stable for one month.

The protocol conformed to the Declaration of Helsinki and all amendments and was 
approved by the local ethics committees of all the participating hospitals. All the patients were informed of the nature and purpose of the study and gave their written consent.

The enrolment of patients by centre ranged from 1 to 32 with a median value of 6 . Of the 337 patients screened 334 were randomised (167 in each treatment group), using a computer generated list prepared by SmithKline Beecham, to receive, at bedtime, over a four week period, either $2 \mathrm{~g}$ mesalazine foam enema, given rectally in two metered applications (total volume $120 \mathrm{ml}$ ) or $20 \mathrm{mg}$ prednisolone foam enema given rectally in one metered application (total volume $30 \mathrm{ml}$ ). Both treatments were presented as blank cylindrical aerosol cans with disposable applicators, however, the prednisolone can was approximately half the size of the mesalazine cans. To maintain investigator blindness every effort was made to ensure they did not see the cans.

Patients were provided with loperamide capsules as escape antidiarrhoeal medication if clinically indicated.

At screening, patients were examined by flexible or rigid sigmoidoscopy or colonoscopy and a biopsy specimen taken to confirm the diagnosis. Stool culture was performed to exclude enteropathogens and a blood sample taken for baseline haematology and biochemistry tests. Patients' demography, medical history, current symptoms, and concomitant medication were recorded. Once randomised, patients were asked to complete a symptom diary card during the study period, and the data were collected at each visit. Patients returned to the clinic for repeat clinical assessments after two weeks (14 \pm 3 days) and four weeks (28 \pm 3 days) when symptom assessment (rectal bleeding and mucus, stool frequency and consistency, abdominal pain, urgency, incontinence, and tenesmus), global symptom improvement, concomitant medication, and adverse events were recorded. A repeat sigmoidoscopy and biopsy was undertaken at week 4 along with repeat haematology and biochemistry tests. Where possible any patients withdrawn during the study period underwent a repeat sigmoidoscopy, biopsy, and provided a blood sample at the time of withdrawal. Clinical remission was defined as $\leqslant 3$ stools/day with no blood.

Sigmoidoscopy enabled the appearance of the mucosa to be graded as I (normal findings including minor abnormalities in the vascular pattern), II (abnormal loss of vascular pattern with mucosal granulation but without bleeding), or III (abnormal with visible bleeding, including ulceration). Sigmoidoscopic remission was defined as grade 1 at week 4 or at withdrawal.

Biopsy specimens taken during the sigmoidoscopic examination were sent to a single blinded consultant histopathologist for grading. Each patient was assigned an 'active inflammation' score ${ }^{9}$ (minimum 0 , maximum 9) along with a descriptive assessment of the histopathology. Histological remission was defined as an active inflammation score of 0 at week 4 or at withdrawal in patients where the score was greater than 0 at entry.
Safety was assessed by haematological (full blood count, platelets and erythrocyte sedimentation rate) and biochemical (urea, creatinine, albumin, bilirubin, alkaline phosphatase, serum aspartate aminotransaminase, and alanine aminotransferase) assessments at week 0 and week 4 and by recording of adverse events either observed by the investigator or reported by the patient at each follow up visit.

\section{Statistical methods}

Two hundred and eighty patients were required to complete the study assuming an $80 \%$ improvement with prednisolone compared with mesalazine. This sample size enabled significance testing at the $5 \%$ level to have an $80 \%$ probability of detecting a true difference between treatments of $15 \%$.

Of the 334 patients randomised, 295 patients were included in the efficacy evaluable population. These patients had no major protocol violations and had received at least 11 days of randomised treatment. Thirty nine patients (18 in the 5-ASA group and 21 receiving prednisolone) were excluded from the analysis; the main reason being that they had received oral corticosteroid treatment or had changed the dose of their oral mesalazine/ sulphasalazine medication in the previous month (nine in the 5-ASA group and 17 receiving prednisolone). Other reasons for excluding data were that patients had Crohn's disease, were non-compliant, or had a normal sigmoidoscopy at entry.

Statistical analysis, by an external consultant, was performed using the MantelHaenszel $\chi^{2}$ test and Wilcoxon rank sum test. Previous use of prednisolone foam enema and concurrent use of mesalazine or sulphasalazine were introduced as strata. Treatments were compared using two sided tests with a nominal significance level of $p=0.05$. The results were expressed as the difference between the two groups along with the $95 \%$ confidence intervals around the difference. No adjustments were made to the $p$ values to account for multiple testing, but statistical tests were kept to a minimum.

\section{Results}

Of the 295 eligible patients 149 received mesalazine $2 \mathrm{~g}$ and 146 received prednisolone foam enema $20 \mathrm{mg}$. Both groups were well matched with respect to age (range 18-88 years), sex, previous ulcerative colitis history, disease extent, and concurrent mesalazine/ sulphasalazine use (Table I). Altogether 40 patients withdrew from the study, the main reason being lack of efficacy (five patients in the mesalazine group, 13 patients in the prednisolone group). A further three patients were excluded from the week 4 analysis for being outside of the specified visit window.

At entry all eligible patients had an abnormal sigmoidoscopy, the median grade was III. The median 'active inflammation score' was 7 in both treatment groups. Thus most patients had a moderately inflamed rectal mucosa 
TABLE I Patients' ulcerative colitis history

\begin{tabular}{|c|c|c|}
\hline Characteristics & $\begin{array}{l}\text { 5- } A S A \text { foam } \\
\text { enema } \\
(n=149)\end{array}$ & $\begin{array}{l}\text { Prednisolone } \\
\text { foam enema } \\
(n=146)\end{array}$ \\
\hline \multicolumn{3}{|l|}{$\operatorname{Sex}(\%)$} \\
\hline Male & $76(51)$ & $80(55)$ \\
\hline Female & $73(49)$ & $66(45)$ \\
\hline \multicolumn{3}{|l|}{ Age $(y)$} \\
\hline Mean & 44 & 45 \\
\hline SD & $13 \cdot 6$ & $15 \cdot 0$ \\
\hline \multicolumn{3}{|c|}{ Previous history of ulcerative colitis (\%) } \\
\hline $\begin{array}{l}\text { Yes } \\
\text { No }\end{array}$ & $128(86)$ & $\begin{array}{r}125(86) \\
21(14)\end{array}$ \\
\hline \multicolumn{3}{|l|}{ Median duration present } \\
\hline symptoms (weeks) & 8 & 6 \\
\hline \multicolumn{3}{|l|}{ Disease extent $(\%)$} \\
\hline Proctitis & $14(9)$ & $15(10)$ \\
\hline Sigmoiditis & $97(66)$ & $101(71)$ \\
\hline Left sided colitis & $37(25)$ & 27 (19) \\
\hline Not known & 1 & 3 \\
\hline \multicolumn{3}{|c|}{ Concomitant oral 5-ASA/SSZ (\%) } \\
\hline Yes & $63(42)$ & $69(47)$ \\
\hline No & $86(58)$ & $77(53)$ \\
\hline
\end{tabular}

(Table II). Baseline symptoms were well balanced between treatment groups (Table III).

\section{Efficacy assessments}

Table II shows that after four weeks patients in both treatment groups had improved sigmoidoscopically with a median in both groups of grade II. The median 'active inflammation score' was 2 in the mesalazine group and 3 in the prednisolone group.

Clinical remission was achieved by significantly more patients treated with mesalazine than with prednisolone $(52 \% v 31 \% \mathrm{p}<0.001)$ (Figure). The 95\% confidence intervals (CI) indicate that the treatment difference may be between $10 \%$ and $32 \%$ in favour of mesalazine.

There was no statistically significant difference between treatment groups in terms of sigmoidoscopic remission or histological remission. However, for both assessments there was a trend in favour of patients treated with mesalazine; for sigmoidoscopic remission $40 \% v 31 \%(\mathrm{p}=0.10)$ and for histological remission $27 \% \vee 21 \%(\mathrm{p}>0.2)$ (see Figure).

Summary data recorded at week 4 showed that symptoms improved for patients in both treatment groups with no statistically significant differences except for blood in the stools (see Table III). Mesalazine patients were statistically significantly less likely to have blood in the stools after four weeks of treatment, $67 \% v$

TABLE II Sigmoidoscopy and histology results at entry and after four weeks of treatment

\begin{tabular}{|c|c|c|c|c|}
\hline & \multicolumn{2}{|l|}{ Week 0} & \multicolumn{2}{|l|}{ Week 4} \\
\hline & $\begin{array}{l}5-A S A \\
\text { foam enema }\end{array}$ & $\begin{array}{l}\text { Prednisolone } \\
\text { foam enema }\end{array}$ & $\begin{array}{l}5-A S A \\
\text { foam enema }\end{array}$ & $\begin{array}{l}\text { Prednisolone } \\
\text { foam enema }\end{array}$ \\
\hline \multicolumn{5}{|l|}{ Sigmoidoscopy } \\
\hline Normal (\%) & 0 & 0 & $59(47)$ & $44(35)$ \\
\hline Abnormal without visible bleeding (\%) & $62(49)$ & $57(45)$ & $52(42)$ & $62(50)$ \\
\hline Abnormal with visible bleeding (\%) & $64(51)$ & $69(55)$ & $14(11)$ & $19(15)$ \\
\hline Not known & 0 & 0 & 1 & 1 \\
\hline Median category & 3 & 3 & 2 & 2 \\
\hline No of patients & 126 & 126 & 126 & 126 \\
\hline \multicolumn{5}{|l|}{ Active inflammation score (range: $0-9$ ) } \\
\hline Median category & 7 & 7 & 2 & 3 \\
\hline Minimum category & 1 & 2 & 0 & 0 \\
\hline Maximum category & 9 & $\overline{9}$ & 9 & 9 \\
\hline No result & 6 & 3 & 4 & 5 \\
\hline No of patients $\star$ & 116 & 116 & 118 & 114 \\
\hline
\end{tabular}

* Omitting those patients in either group who had a result of 0 at week 0 (for the active inflammation score) or no result available.
$40 \%$ had no blood $(\mathrm{p}<0.001)$, the $95 \%$ CI indicate that the treatment difference may be between $16 \%$ and $40 \%$ in favour of mesalazine.

The diary card data confirmed the summary data and found a reduced number of days during week 4 with blood in the stools of patients treated with mesalazine foam enema $(p<0 \cdot 001)$. Diary data also showed significantly fewer days with tenesmus in mesalazine recipients $(p=0.038)$. Tenesmus occurred on two or more days in week 4 for $15 \%$ patients treated with mesalazine and for $29 \%$ patients treated with prednisolone.

Conversely, patients treated with prednisolone had significantly fewer days with abnormal stool consistency compared with mesalazine $(p=0.001)$. Abnormal stools occurred on three or more days in week 4 for $39 \%$ of patients treated with mesalazine compared with $23 \%$ of patients treated with prednisolone.

After four weeks of treatment $87 \%$ of mesalazine patients and $80 \%$ of prednisolone patients reported a global improvement in their symptoms $(p=0 \cdot 19)$, while $3 \%$ and $6 \%$ of patients respectively reported a global deterioration in symptoms.

\section{Safety assessments}

No clinically significant changes in haematological or biochemical parameters were noted. Both treatments were well tolerated.

As might be expected the most common adverse events affected the gastrointestinal tract, with abdominal pain and bloating being the most common (Table IV).

Five patients withdrew from the study because of adverse events. Of the three patients withdrawn from the mesalazine group one suffered a pulmonary embolus, one had an elective prostatectomy, and the other had severe abdominal pain with rectal discharge. Only the last of these was considered drug related. The two prednisolone patients withdrawn for adverse events were due to a pulmonary embolus in one and eczema around the pubic area and back in the other, again only the second of these was considered related to study medication.

\section{Discussion}

Compared with topical prednisolone foam, mesalazine foam enema was associated with a significantly higher clinical remission rate, significantly fewer days with blood in the stools, and significantly fewer days of tenesmus and there were trends favouring better sigmoidoscopic and histological remission rates. Prednisolone foam enema on the other hand was found to produce significantly fewer days with abnormal stool consistency.

Over a longer treatment period we may have seen the trends favouring better sigmoidoscopic and histological remission in the mesalazine group become more significant as it has been shown in previous studies that histological improvement lags behind symptomatic improvement. ${ }^{10}$ 
TABLE III Symptoms at entry and after four weeks of treatment

\begin{tabular}{|c|c|c|c|c|c|}
\hline & \multicolumn{2}{|l|}{ Week 0} & \multicolumn{2}{|l|}{ Week 4} & \multirow[b]{2}{*}{$\begin{array}{l}p \text { Value } \\
\text { (week } 4 \\
\text { difference) }\end{array}$} \\
\hline & $\begin{array}{l}5-A S A \\
\text { foam enema } \\
(n=149)\end{array}$ & $\begin{array}{l}\text { Prednisolone } \\
\text { foam enema } \\
(n=146)\end{array}$ & $\begin{array}{l}5-A S A \\
\text { foam enema } \\
(n=126)\end{array}$ & $\begin{array}{l}\text { Prednisolone } \\
\text { foam enema } \\
(n=126)\end{array}$ & \\
\hline \multicolumn{6}{|c|}{ Average no of stools per day } \\
\hline Median & 4 & 4 & 2 & 2 & \multirow{3}{*}{$p>0 \cdot 2$} \\
\hline Minimum & $<1$ & 0 & 1 & 1 & \\
\hline Maximum & 20 & 15 & 13 & 15 & \\
\hline \multicolumn{6}{|l|}{ Stool consistency } \\
\hline Normal (\%) & $38(26)$ & $29(20)$ & $82(66)$ & $93(74)$ & \multirow{3}{*}{$p=0.17$} \\
\hline Liquid (\%) & $109(74)$ & $114(80)$ & $43(34)$ & $33(26)$ & \\
\hline Not known & 2 & 3 & 1 & 0 & \\
\hline \multicolumn{6}{|l|}{ Blood in stools } \\
\hline No $(\%)$ & $11(7)$ & $7(5)$ & $85(67)$ & $50(40)$ & \multirow{3}{*}{$\mathrm{p}<0.001$} \\
\hline Yes $(\%)$ & $138(93)$ & 139 (95) & $41(33)$ & $76(60)$ & \\
\hline \multicolumn{5}{|l|}{ Mucus in stools } & \\
\hline $\begin{array}{l}\text { No }(\%) \\
\text { Yes }(\%)\end{array}$ & $\begin{array}{r}24(16) \\
125(84)\end{array}$ & $\begin{array}{r}15(10) \\
131(90)\end{array}$ & $\begin{array}{l}73(58) \\
53(42)\end{array}$ & $\begin{array}{l}64(51) \\
62(49)\end{array}$ & $\mathrm{p}>0 \cdot 2$ \\
\hline \multicolumn{6}{|l|}{ Urgency } \\
\hline No $(\%)$ & $19(13)$ & $13(9)$ & $80(63)$ & $82(65)$ & \multirow{3}{*}{$p>0 \cdot 2$} \\
\hline Yes $(\%)$ & $130(87)$ & $132(91)$ & $46(37)$ & $44(35)$ & \\
\hline Not known & 0 & 1 & 0 & 0 & \\
\hline \multicolumn{6}{|l|}{ Incontinence } \\
\hline $\begin{array}{l}\text { No }(\%) \\
\text { Yes }(\%)\end{array}$ & $\begin{array}{r}108(72) \\
41(28)\end{array}$ & $\begin{array}{r}115(79) \\
31(21)\end{array}$ & $\begin{array}{r}111(88) \\
15(12)\end{array}$ & $\begin{array}{c}118(94) \\
8(6)\end{array}$ & \multirow{2}{*}{$\mathrm{p}=0.14$} \\
\hline \multicolumn{5}{|l|}{ Tenesmus } & \\
\hline $\begin{array}{l}\text { No }(\%) \\
\text { Yes }(\%)\end{array}$ & $\begin{array}{l}72(48) \\
77(52)\end{array}$ & $\begin{array}{l}68(47) \\
78(53)\end{array}$ & $\begin{array}{r}102(81) \\
24(19)\end{array}$ & $\begin{array}{l}97(78) \\
28(22)\end{array}$ & \multirow[t]{2}{*}{$\mathrm{p}>0 \cdot 2$} \\
\hline Not known & 0 & 0 & 0 & 1 & \\
\hline \multicolumn{6}{|l|}{ Abdominal pain } \\
\hline $\begin{array}{l}\text { No }(\%) \\
\text { Yes }(\%)\end{array}$ & $55(37)$ & $59(40)$ & $89(71)$ & $86(68)$ & \\
\hline Yes $(\%)$ & $94(63)$ & $87(60)$ & $37(29)$ & $40(32)$ & $\mathrm{p}>0.2$ \\
\hline
\end{tabular}

In terms of the improvement in other disease parameters, including symptoms such as incontinence, abdominal pain, and frequency there was no difference seen between the two treatments. Both treatments were well tolerated with similar adverse event profiles and no significant changes in haematological or biochemical parameters.

The higher clinical remission rate found in the mesalazine group was caused in part by the highly significant reduction in the number of patients with blood in stools that occurred in this treatment group, an effect that may relate to several factors such as the intrinsic activity of mesalazine on the ulcerated mucosa relative to corticosteroids, the adherence properties of the foam, and the larger volume/better spread of the mesalazine. The difference in volumes between the two drugs may, however, explain the fewer days with abnormal stool consistency associated with the use of prednisolone.

Oral formulations of mesalazine and sulphasalazine have been used for many years in the treatment of acute ulcerative colitis, ${ }^{1}$ acting topically in the colon probably by reducing the acute inflammatory response. ${ }^{11}$ Treatment of

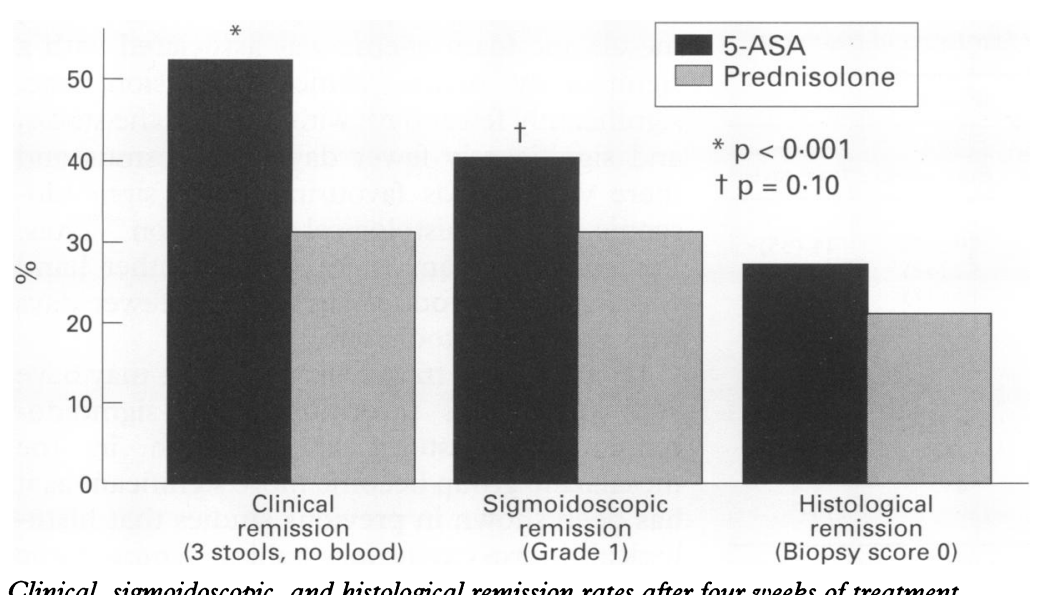

TABLE IV Most common adverse events (number (\%) of patients)

\begin{tabular}{lll}
\hline & \multicolumn{2}{l}{ Foam enema } \\
\cline { 2 - 3 } Events & $5-A S A$ & $\begin{array}{l}\text { Prednisolone } \\
(n=167)\end{array}$ \\
\hline Patients with $\geqslant 1$ event & $57(34)$ & $43(26)$ \\
Bloating & $10(6)$ & $2(1)$ \\
Abdominal pain & $12(7)$ & $7(4)$ \\
Deterioration of ulcerative colitis & $5(3)$ & $7(4)$ \\
Nausea and vomiting & $5(3)$ & $7(4)$ \\
Headache & $7(4)$ & $4(2)$ \\
\hline
\end{tabular}

distal ulcerative colitis can easily be given via the rectum thus permitting direct topical coverage of the inflamed mucosa and a low level of systemic absorption. ${ }^{12}$ Therefore rectal formulations of mesalazine have been developed, namely suppositories and retention enemas. A number of studies have shown that mesalazine liquid enemas are highly effective in acute ulcerative colitis provided the disease does not extend beyond the splenic flexure. ${ }^{4-7}$

Mesalazine foam enema preparations have been developed recently; work by Campieri on an early Italian mesalazine foam enema showed that when given in equal doses of $2 \mathrm{~g}$ a prompter remission was obtained in patients receiving a foam rather than liquid enema. Furthermore $81 \%$ of the patients expressed a preference for the foam as it was easier to retain and more comfortable and practical to use. ${ }^{8}$ This may be due to the tendency of foam preparations to adhere to the colonic mucosa, even after bowel evacuations. ${ }^{13}$

The extent of spread of the mesalazine foam enema used in this study has been investigated and found to disperse well into the descending colon and in some instances up to and beyond the splenic flexure (unpublished finding). Retrograde spread of enema preparations is dependent on enema volume and the larger volume of the mesalazine foam enema compared with the prednisolone enema $(120 \mathrm{ml} v$ $30 \mathrm{ml}$ ) may explain in part the greater efficacy seen in this study (all the commercially available corticosteroid foam enemas are of comparable volume).

Systemic absorption of mesalazine from the foam enema has been investigated and was found to be similar to that of other marketed mesalazine preparations (unpublished finding), suggesting the foam enema will be a safe and effective treatment for patients with ulcerative colitis.

The prolonged use of corticosteroid enemas including prednisolone foam enemas is undesirable as they are readily absorbed from the rectum and distal colon and are a potential cause of systemic side effects. A new mesalazine foam enema will therefore provide an effective alternative treatment without the side effects associated with the systemic absorption of corticosteroids. ${ }^{14}$

In conclusion mesalazine foam enema is a highly efficacious and well tolerated preparation for the treatment of patients with acute distal ulcerative colitis.

We would like to thank the following for their contribution to the above study: Dr S P Wilkinson, Dr R Burnham, Dr I Cobden, Dr M J Goodman, Professor C Hawkey, Mr G Hutchinson, 
Dr G Neale, Dr P Down, Dr P Evans, Dr P Cann, Dr J L Shaffer, Dr A Axon, Dr C Pennington, Dr I Barrison, Dr G Allan, Dr I Chesner, Dr J Collins, Dr P B McIntyre, Dr R J Dickinson, Mr R Leicester, Professor J E Lennard-Jones, Dr A Manning, Dr J Wilson, Dr D G Colin-Jones, Dr T Daneshmund, Dr M E Denyer, Dr S B Desai, Professor M Farthing, Dr M Grayson, Dr R Lendrum, Dr P Trewby. Farthing, Dr M Grayson, Dr R Lendrum, Dr P Trewby. Funding was

This study was presented as a poster at the 1994 Spring meeting of the British Society of Gastroenterology at Manchester and was published as an abstract (Gut 1994; 35 (suppl 2): S42).

1 Riley SA, Mani V, Goodman MJ, Herd ME, Dutt S, Turnberg LA. Comparison of delayed-release 5-aminosalicylic acid and sulphasalazine in the treatment of mild to moderate ulcerative colitis relapse. Gut 1988; 29: 669-74.

2 Dew MJ, Hughes P, Harries AD, Williams G, Evans BK, Rhodes J. Maintenance of remission in ulcerative colitis with an oral preparation of 5 -aminosalicylic acid. $B M \mathcal{J}$ 1982; 285: 1012 .

3 Riley SA, Mani V, Goodman MJ, Herd ME, Dutt S, Turnberg LA. Comparison of delayed-release 5-aminosalicylic acid and sulfasalazine as maintenance treatment for patients with ulcerative colitis. Gastroenterology 1988; 94: 1383-9.

4 Sutherland LR, Martin F, Greer S, Robinson M, Greenberger N, Saibil F, et al. 5-aminosalicylic acid enema in the treatment of distal ulcerative colitis, proctosigmoiditis and prochitis. Gastroenterology 1987; 92: 1894-8.

5 Willoughby CP, Campieri M, Lanfranchi G, Truelove SC, Jewell DP. 5-Aminosalicylic acid (Pentasa) in enema form for the treatment of active ulcerative colitis. Ital $\mathfrak{f}$ Gastroenterol 1986; 18: 15-7.
6 Danish 5-ASA Study Group. Topical 5-aminosalicylic acid versus prednisolone in ulcerative proctosigmoiditis. Dig Dis Sci 1987; 32: 598-602.

7 Campieri M, Lanfranchi GA, Bazzocchi G, Brignola C, Sarti F, Franzin G, et al. Treatment of ulcerative colitis with high dose 5-aminosalicylic acid enemas. Lancet 1981; ii: $270-1$.

8 Campieri M, Paoluzi P, D'Albasio G, Brunette G, Pera A, Barbara L. Better quality of therapy with 5-ASA colonic foam in active ulcerative colitis. A multicentre comparafoam in active ulcerative colitis. A multicentre comparative trial

9 Ruddel WSJ, Dickinson RJ, Dixon MF, Axon ATR. Treatment of distal ulcerative colitis (proctosigmoiditis) in relapse: comparison of hydrocortisone enemas and rectal hydrocortisone foam. Gut 1980; 21: 885-9.

10 O'Donnell LJDO, Arvind AS, Hoang P, Cameron D, Talbot IC, Jewell DP, et al. A double, controlled trial of 4aminosalicylic acid and prednisolone enemas in distal ulcerative colitis. Gut 1992; 33: 947-9.

11 Greenfield SM, Punchard NA, Teare JP, Thompson RPH. Review article: the mode of action of the aminosalicylates in inflammatory bowel disease. Aliment Pharmacol Ther 1993; 7: 369-83.

12 Campieri $M$, Lanfranchi GA, Boschi S, Brignola C, Bazzocchi G, Gionchetti P, et al. Topical administration of 5 aminosalicylic acid enemas in patients with ulcerative colitis. Studies on rectal absorption and excretion. Gut 1985; 26: 400-5.

3 Campieri M, Corbelli C, Gionchetti P, Brignola C, Belluzzi A, DiFebo G, et al. Spread and distribution of 5ASA colonicfoam (Asacol) and 5ASA enema in patients with ulcerative colitis. Dig Dis Sci 1992; 37: 1890-7.

14 McIntyre PB, Macrea FA, Berghouse L, English J, Lennard Jones JE. Therapeutic benefits from a poorly absorbed prednisolone enema in distal colitis. Gut 1985; 26: 822-4. 